Vietnam Journal of Mechanics, NCST of Vietnam Vol. 24, 2002, No2 (84 - 100)

\title{
NUMERICAL STUDY OF THE RECIRCULATION ZONE BEHIND A BUILDING IN THE NEUTRAL AND STABLE ATMOSPHERIC BOUNDARY LAYER
}

\author{
Duong Ngoc HaI, NGuYen The DuC \\ Institute of Mechanics, NCST, 264 Doican, Hanoi, Vietnam
}

\begin{abstract}
The objective of the paper is to study numerically, using $k-\varepsilon$ model, the circulation zone behind a building under neutral and stable conditions. The influences of wind speed, vertical gradient of the temperature, surface roughness and building height on the length and structure of the recirculation zone are investigated. The research result showed that the recirculation area extends from immediately behind the building to a distance of about 2.5 times, in maximum, of the dimension of the building. The recirculation zone's length increases with the increase of wind speed, decreases with the increase of vertical gradient of the temperature, decreases with the increase of roughness and increases with the increase of building height. Some exceptions of two last tendencies may occur for the cases of high surface roughness or high building, when the flow shift from a simple one-vortex to a complex multiple-vortex structure.
\end{abstract}

\section{Introduction}

For flow approaching to an obstacle, some recirculation zones may be created by flow separation from the edges of the obstacle. The largest recirculation zone is usually behind the obstacle. The appearance of this zone strongly influences on the transport and diffusion characteristics of pollutants around the obstacle. These influences have been observed in many expreriments (see e.g. [1], [2], [3]). The pollutant's concentration may be very high as the sources are set in recirculation zones. For example, the high air pollution near Ninh Binh power station in the past very possibly is concerned with the recirculation zone behind Canh Dieu mountain. In the cities, these bad influences also may be observed near building or in street canyons.

Because of undesirable recirculation zone's effects, some studies were performed on this problem. The description of the recirculation zones near the obstacles is generally based on flow visualization and measurements on experimental models of wind and water tunnels. Many of these studies treated cubical obstacles. For flow approaching normal to the cubical building face, a recirculation zone is created.

In light of these studies, there are many qualitative and also quantitative things, which are needed to investigate, about the air flow in the vicinity of the building, especially about the recirculation behind the building. Therefore the numerical studies in this field are necessary.

The air flows near obstacle are very complicated and highly turbulent. To analyse 
these turbulent flows, it is therefore important to develop specific techniques and reliable tools. Most atmospheric models are hydrostatic (see e.g. [4], [5], [6]). They cannot be used to treat the recirculation zone, because they neglect the acceleration of vertical velocity. In addition, although the application of first-oder turbulent closure ( $K$ theory) has been widespread in atmospheric studies (see e. g. [7], [8], [9]), it is difficult to express $K$ analytically or to measure it for flow over complex terrain ([10], [11]). Because of the extreme high sensitivity of the turbulent flow field to the varying pressure gradients caused by the terrain, these models are not applicable to the case of complex terrain and thus a realistic description of the turbulent structure requires considerably more sophisticated closures.

This paper presents some results of numerical studies of flow structure and recirculation zone behind the building. A nonhydrostatic model based on $k-\varepsilon$ turbulent closure scheme was used. This $k-\varepsilon$ model includes some Duynkerke's modifications for atmospheric applications. Some factors, which have important influences to the flow field near the building including wind speed, vertical gradient of the temperature (atmosphere stability), surface roughness and building height, are investigated.

\section{Descriptions of numerical simulation}

\subsection{Governing equations}

The Reynolds-averaged Navier-Stokes equations governing the motion of turbulent flows may be written as follows:

$$
\begin{aligned}
& \frac{\partial \rho}{\partial t}+\frac{\partial\left(\rho U_{i}\right)}{\partial x_{i}}=0 \\
& \frac{\partial U_{i}}{\partial t}+U_{j} \frac{\partial U_{i}}{\partial x_{j}}=-\frac{\partial\left(\overline{u_{i}^{\prime} u_{j}^{\prime}}\right)}{\partial x_{j}}-\frac{1}{\rho_{0}} \frac{\partial \delta P}{\partial x_{i}}+\frac{\delta \rho}{\rho_{0}} g_{i} \\
& \frac{\partial \theta}{\partial t}+U_{j} \frac{\partial \theta}{\partial x_{j}}=-\frac{\partial\left(\overline{\theta^{\prime} u_{j}^{\prime}}\right)}{\partial x_{j}}
\end{aligned}
$$

where $x_{i}$ are the Cartesian coordinates; $U_{i}$ are the components of the mean velocity; $g_{i}=(0,0,-g)$ are the components of the gravitational acceleration; $\delta \rho$ is the deviation of density $\rho$ from its reference value $\rho_{0} ; \delta P$ is the deviation of pressure $P$ from its reference value $P_{0} ; u_{i}^{\prime}$ and $\theta^{\prime}$ are the fluctuations of the velocity components and potential temperature around their mean; $\overline{u_{i}^{\prime} u_{j}^{\prime}}$ is the Reynolds stress tensor and $\overline{u_{i}^{\prime} \theta^{\prime}}$ is the turbulent heat flux. The subscript 0 refers to the aerostatic and adiabatic reference state. The deep equation of Oruga and Philips [9] has been employed in the present calculations for the reference pressure and density.

The pressure is related to the density and the temperature $T$ through the following equation of state:

$$
P=\rho R_{d} T
$$


with the definition of potential temperature

$$
\Theta=T\left(\frac{P}{P_{0}}\right)^{\frac{R_{d}}{C_{p}}}
$$

where $P_{0}$ is the surface pressure at $z=0 ; R_{d}$ is the gas constant for dry air $\left(R_{d}=\right.$ $287 \mathrm{Jkg}^{-1} \mathrm{~K}^{-1}$ ) and $C_{p}$ is the specific heat at constant pressure for air. For dry air, the isobaric specific heat $C_{p}$ has weak temperature dependence given by [12]:

$$
C_{p}=1005+(T-250)^{2} / 3364 \mathrm{Jkg}^{-1} K^{-1} .
$$

The $k-\varepsilon$ turbulent model is used to close the mean flow equations (see [10], [11], [12]). The Reynold stresses $\overline{u_{i}^{\prime} u_{j}^{\prime}}$ and the turbulent heat flux $\overline{u_{i}^{\prime} \theta^{\prime}}$ are estimated by means of the Boussinesq's eddy viscosity and eddy diffusivity models:

$$
\begin{aligned}
& \overline{u_{i}^{\prime} u_{j}^{\prime}}=-\nu_{t}\left(\frac{\partial U_{i}}{\partial x_{j}}+\frac{\partial U_{j}}{\partial x_{i}}\right)+\frac{2}{3} \delta_{i j} k \\
& \overline{u_{i}^{\prime} \theta^{\prime}}=-K_{t} \frac{\partial \theta}{\partial x_{i}}
\end{aligned}
$$

where $\nu_{t}$ is the eddy viscosity; $\delta_{i j}$ is the Kronecker delta; $k$ is the turbulent kinetic energy (TKE) and $K_{t}$ is a turbulent diffusivity coefficient. Experiments indicate that $\nu_{t}$ and $K_{t}$ are not constant, but vary within a flow and from one flow to another by the way that their ratios - the turbulent Prandtl number $P r_{t}=\frac{\nu_{t}}{K_{t}}$ - is roughly constant.

Therefore, the closure problem is reduced to determine the distribution of $\nu_{t}$. This question can be empirically related to two parameters that are assumed to be characteristics, which characterize the local state of turbulence: a velocity scale and a length scale. The $k-\varepsilon$ models express the turbulence velocity scale as $k^{1 / 2}$ and the turbulence length scale as $k^{3 / 2} \varepsilon^{-1}$. These permit the formation of the eddy viscosity as following:

$$
\nu_{t}=c_{\mu} \frac{k^{2}}{\varepsilon}
$$

where $c_{\mu}$ is an empirical constant.

The turbulent kinetic energy $k$ and its dissipation rate $\varepsilon$ are calculated from the following semi-empirical transport equations

$$
\begin{aligned}
& \frac{\partial k}{\partial t}+U_{j} \frac{\partial k}{\partial x_{j}}=\frac{\partial}{\partial x_{j}}\left(\frac{\nu_{t}}{\sigma_{k}} \frac{\partial k}{\partial x_{i}}\right)+S+G-\varepsilon \\
& \frac{\partial \varepsilon}{\partial t}+U_{t} \frac{\partial \varepsilon}{\partial x_{j}}=\frac{\partial}{\partial x_{j}}\left(\frac{\nu_{t}}{\sigma_{\varepsilon}} \frac{\partial \varepsilon}{\partial x_{j}}\right)+\frac{\varepsilon}{k}\left(c_{1 \varepsilon} S+c_{3 \varepsilon} G-c_{2 \varepsilon} \varepsilon\right)
\end{aligned}
$$


where $\sigma_{e}, \sigma_{\varepsilon}, c_{1 \varepsilon}, c_{2 \varepsilon}$ and $c_{3 \varepsilon}$ are constants; $S$ is the shear production term and $G$ is the buoyancy term in the TKE equation, defined as following:

$$
\begin{aligned}
& S=\nu_{t}\left(\frac{\partial U_{i}}{\partial x_{j}}+\frac{\partial U_{j}}{\partial x_{i}}\right) \frac{\partial U_{i}}{\partial x_{j}}, \\
& G=\frac{\nu_{t}}{\sigma_{t}} \frac{g}{\rho_{0}} \frac{\partial \rho}{\partial z} .
\end{aligned}
$$

In the above presented equations, the standard values of the constants, which have been used for most engineering applications, are given in Table 1.

\subsection{Two modifications of the $k-\varepsilon$ model}

The standard $k-\varepsilon$ model has been shown to work quite well in the engineering field for many different flows. However, in its atmospheric applications, based on experimental data, some authors recommended making some changes to the standard $k-\varepsilon$ model: In a modification [13], Detering and Etling suggested modifying the $\varepsilon$ equation for better reflect characteristic turbulent length scale above the region with strong shear (surface region) in the atmospheric boundary layer. They proposed reducing $\varepsilon$ by modifying the $c_{1 \varepsilon}$ and the $c_{3 \varepsilon}$ constants. Instead of them, they used the following constant $c_{1 \varepsilon}^{\prime}$ :

$$
c_{1 \varepsilon}^{\prime}=\frac{c_{1 \varepsilon} L}{h}
$$

where $L$ is the scale of the dominant turbulent eddies and $h$ is a characteristic scale for the atmospheric boundary layer.

The $k-\varepsilon$ turbulence models assume that the scales of the dominant turbulent eddies are given by:

$$
L=\frac{c_{\mu}^{3 / 4} k^{3 / 2}}{\varepsilon} .
$$

The characteristic scale for the atmospheric boundary layer $h$ is given as:

$$
h=c_{h} \frac{u_{*}}{f}
$$

where $u_{*}$ is the friction velocity; $f$ is the Coriolis parameter, and $c_{h}$ is an empirical constant, which was set by Detering and Etling to an optimum value of 0.0015 . The other modification of Detering and Etling can be seen in Table 1.

The standard $k-\varepsilon$ model constant values are also modified by Duynkerke [14] on the basic of atmospheric data. In his modification, the contribution of the buoyancy in equation (2.9) is neglected when the term is negative. The values of constants in Duynkerke model are given also in Table 1. 
Tab. 1. Constants used in the conventional $k-\varepsilon$ turbulence models

\begin{tabular}{|c|c|c|c|c|c|c|}
\hline Turbulence model & $c_{\mu}$ & $c_{1 \varepsilon}$ & $c_{2 \varepsilon}$ & $c_{3 \varepsilon}$ & $\sigma_{k}$ & $\sigma_{\varepsilon}$ \\
\hline Standard & 0.09 & 1.44 & 1.92 & 1.44 & 1.0 & 1.3 \\
\hline Detering and Etling [13] & 0.026 & * & 1.90 & * & 0.74 & 1.3 \\
\hline Duynkerke [14] & 0.033 & 1.46 & 1.90 & 1.46 & 1.0 & 2.38 \\
\hline
\end{tabular}

\subsection{Numerical method}

The above governing equations are solved following the SIMPLE algorithm described by Patankar [15]. A finite volume method is applied on a staggered grid. The velocity components $U, V$ and $W$ are defined at the cell faces while all other scalar-dependent variables are located at the cell centers. The numerical procedure uses centered differences for the diffusion and source terms and an upwind scheme for the advection terms. The continuity condition on mean velocities is satisfied by means of the pressure-correction method. Matrix equations are solved by lineiteration procedures in conjunction with a tridiagonal solver.

Two new partial differential equations for $k$ and $\varepsilon$ are needed to be solved. According to Ferziger [16], because the time scales associated with the turbulence normally are much shorter than those connected with the mean flow, that is why solving numerically the equations for $k$ and $\varepsilon$ are much stiffer than the flow equations. For this reason, in the numerical solution procedure, one first performs an outer iteration of the momentum and pressure correction equations in which the value of the eddy viscosity is based on the values of $k$ and $\varepsilon$ at the end of the preceding iteration. After this has been completed, an outer iteration of the turbulent kinetic energy and dissipation equations is made. After completing an iteration of the turbulence model equations, we are ready to recalculate the eddy viscosity and start a new outer iteration.

\subsection{Code validation}

By the way of comparison with measurement data, the code has been validated for a flow near the cube [17] and a flow near the cone ([18], [19]). The obtained results showed that the standard $k-\varepsilon$ model and two its presented above modifications give a good prediction for mean flow fields and relatively good prediction of turbulence. We also performed an comparison among standard model and two its modificatons for an air flow around a cone ([18], [19]). From this comparison, Duynkerke's modification have given slightly better agreement with measured results. Therefore, Duynkerke modification is used in this study.

\subsection{Simulated domain and approach flow}

Numerical experiments are performed for flow around a building. The building height and widths are $60 \mathrm{~m}$. The building height may be varied in some case studies. 
The approach flow is perpendicular to one building's side. For calculation domain, the limits of the longitudinal are $x_{\min }=-3.58 \mathrm{H}$ and $x_{\max }=8.33 \mathrm{H}$, where $x$ is measured from the center of the building. The limits of the lateral are $y_{\min }=-3.58 \mathrm{H}$ and $y_{\max }=3.58 \mathrm{H}$, where $y$ is also measured from the center of the building. The limits of the vertical axis are $z_{\min }=0$ and $z_{\max }=4.06 \mathrm{H}$.

A grid of 60 cells length (in $x$ axis), 55 cells width and 37 cells height is used for above presented calculation domain. Figure 1 shows the top (a) and side (b) views of grid. This variable-spaced grid was used in order to increase the resolution in regions where flow gradients are high. The grid was designed to provide the highest resolusion near the ground and the obstacle.

(a)

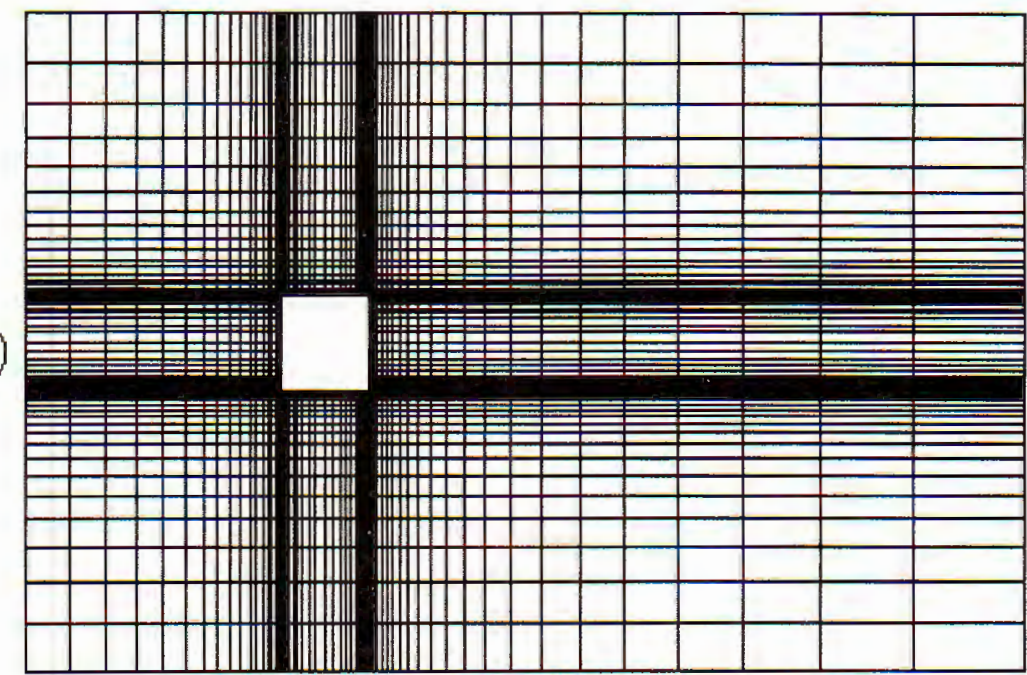

(b)

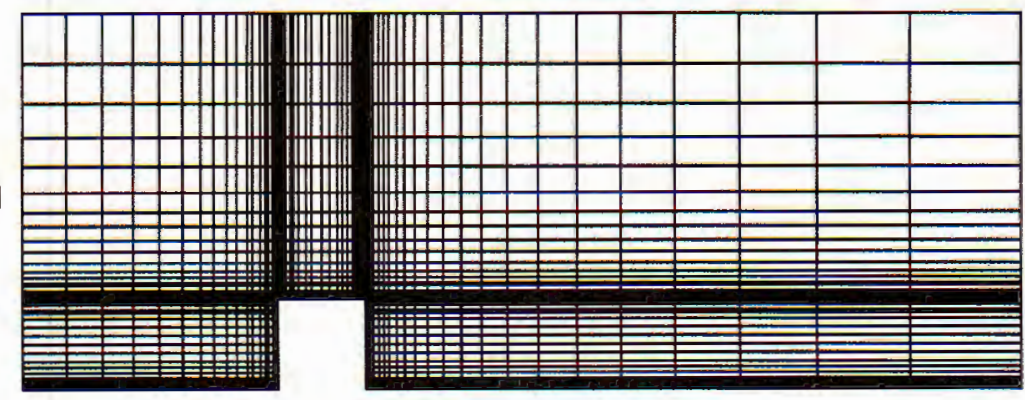

Fig. 1. Grid used in the simulation: (a) top view; (b) side view

The experimental studies in atmospheric boundary layer have shown that in the neutral condition the wind displays nearly logarithmic increase with height above the surface ([12], [20]). The logarithmic wind law is given by following expression: 


$$
\frac{u_{0}(z)}{u_{* 0}}=\frac{1}{\kappa} \ln \left(\frac{z-d}{z_{0}}\right)
$$

where $u_{* 0}$ is the friction velocity; $\kappa$ is the von-Karman constant $(\sim 0.41) ; z_{0}$ is the aerodynamic roughness length and $d$ is the zero-plane displacement.

The logarithmic wind law (2.13) has been used for the description of inflow in this study.

\subsection{Initial and boundary conditions}

The initial conditions for the velocity components are set to zero. The initial conditon for $\theta$, in the case its vertical gradient is known at inflow boundary, is given by:

$$
\theta_{0}=\theta_{s}+\left(\frac{\partial \theta}{\partial z}\right) z
$$

where $\theta_{s}$ is the potential temperature at the ground surface.

The turbulent kinetic energy and its dissipation are specified as follows ([21], [22]):

and

$$
k_{0}=0.003 u_{0}^{2}
$$

$$
\varepsilon_{0}=\frac{C_{\mu}^{3 / 4}}{\kappa z}
$$

No-slip boundary conditions are applied to all solid surfaces. At the inflow boundary, the inflow remains unchanged with time. At the outflow and upper boundaries, the gradient of any variable is set to zero.

\section{Calculation results and discussions}

\subsection{The effect of the inflow wind speed}

To investigate the effect of inflow wind speed on the flow field, three numerical experiments are performed with the wind velocity profile are given by equation (2.13). For the fixed surface roughness $z_{0}=0.001 \mathrm{~m}$, the inflow wind speed at the building height are $u_{H}=3 \mathrm{~m} / \mathrm{s}, u_{H}=5 \mathrm{~m} / \mathrm{s}$ and $u_{H}=7 \mathrm{~m} / \mathrm{s}$, respectively.

With the time step of $\delta t=0.2 s$, approximately $7 \mathrm{~h}$ of CPU time on the PC $500 \mathrm{MHZ}$ are required to reach the steady-state solutions for each numerical simulation (All results presented in this paper are related to steady-state flow). The real time to reach the steady state is about $1.5 \mathrm{~h}$.

The velocity vector fields at the vertical plane through the center of building for different inflow wind speed are shown in Figure 2 (In this and presented later figures 
of flow fields, $x$ in the range from $-H$ to $3.5 H, z$ in the range from 0 to $1.5 H$ ). The velocity vector field at the horizontal plane $z=H / 2$ for the case of $u_{H}=7 \mathrm{~m}$ is shown in Figure 3 ( $x$ in the range from $-H$ to $3.5 H, y$ in the range from $-H$ to $H)$. In according to these three calculations, the lengths of the recirculation zone $L_{r}$ behind the building are $0.814 \mathrm{H}, 1.559 \mathrm{H}$ and $1.781 \mathrm{H}$, respectively. Here and later, the length of the recirculation zones refers to the distance from the faces of building to the farthest point at which the velocity was reversed.

(a)

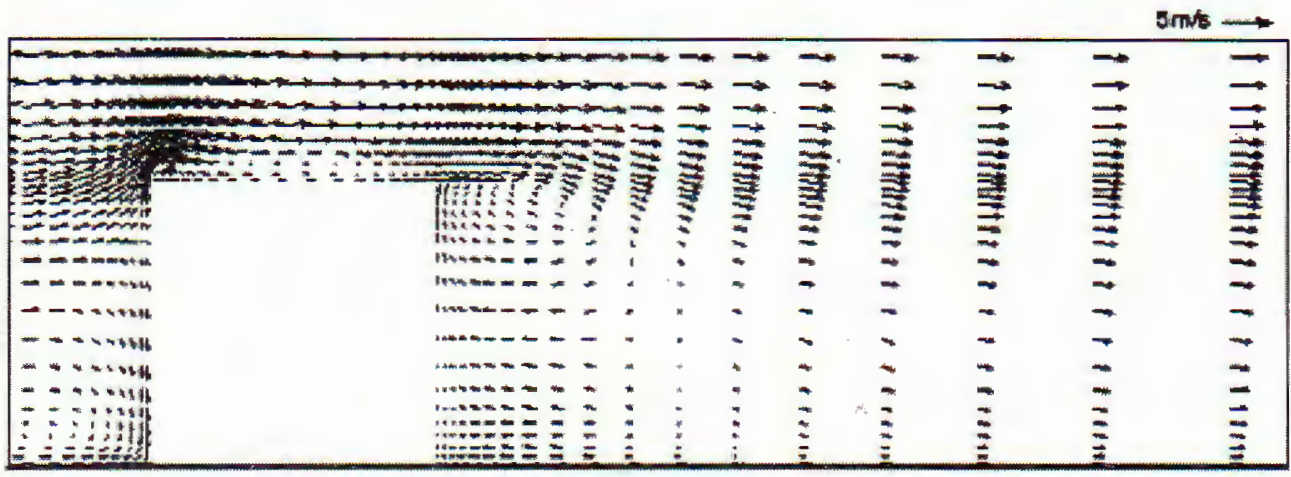

(b)

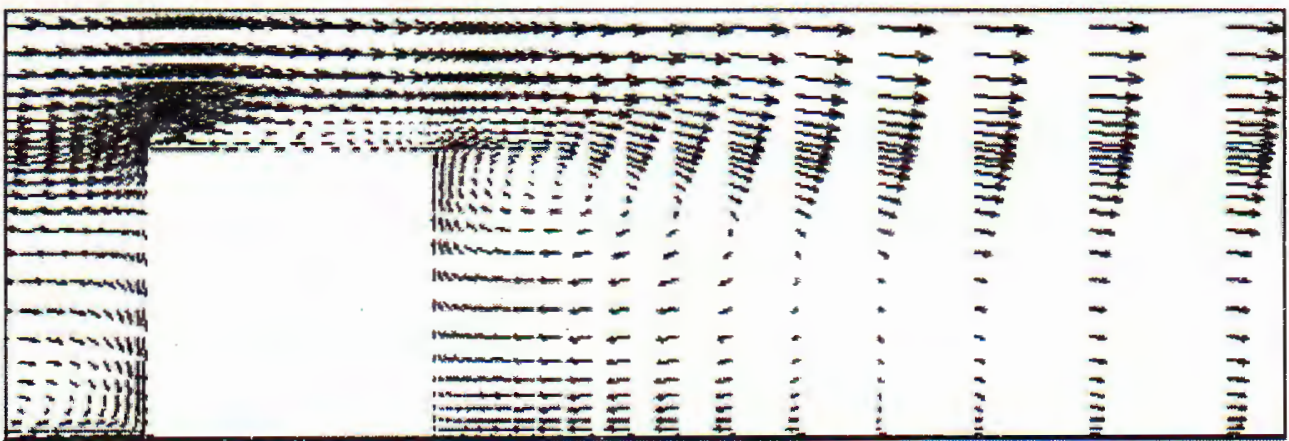

(c)

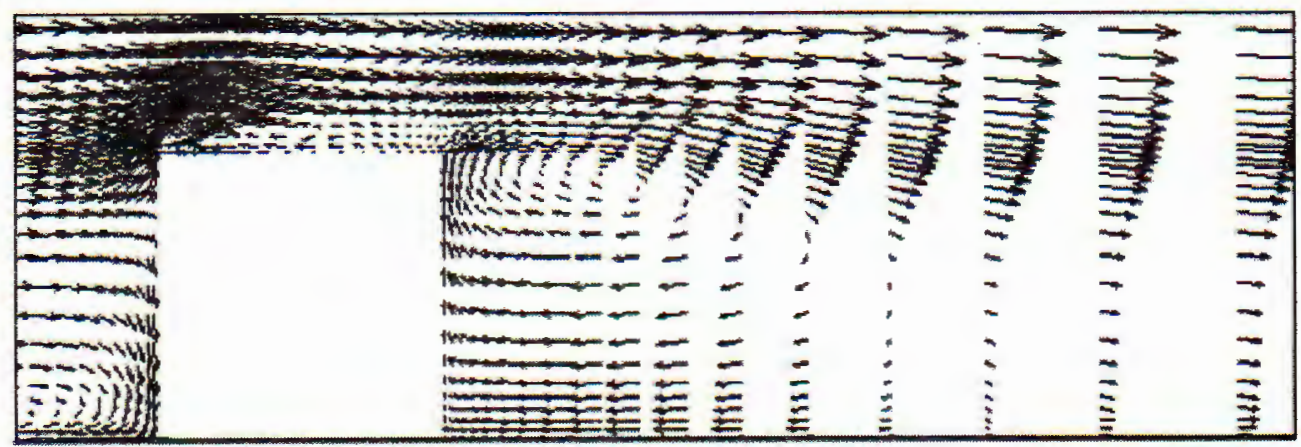

Fig. 2. Velocity vector field in $x-z$ plane through the center of building for

$$
z_{0}=0.001 \mathrm{~m} \text { and: (a) } u_{H}=3 \mathrm{~m} / \mathrm{s} \text {, (b) } u_{H}=5 \mathrm{~m} / \mathrm{s} \text {, (c) } u_{H}=7 \mathrm{~m} / \mathrm{s}
$$

The numerical experiments show that the length of recirculation zone behind the building increases with the wind speed. Some other simulations also were performed 
with larger wind speed and it was found that in these cases the length of recirculation zone slowly increases at large wind speed, approaching an asymptotic value $L_{\tau} \sim$ $2.5 H$.

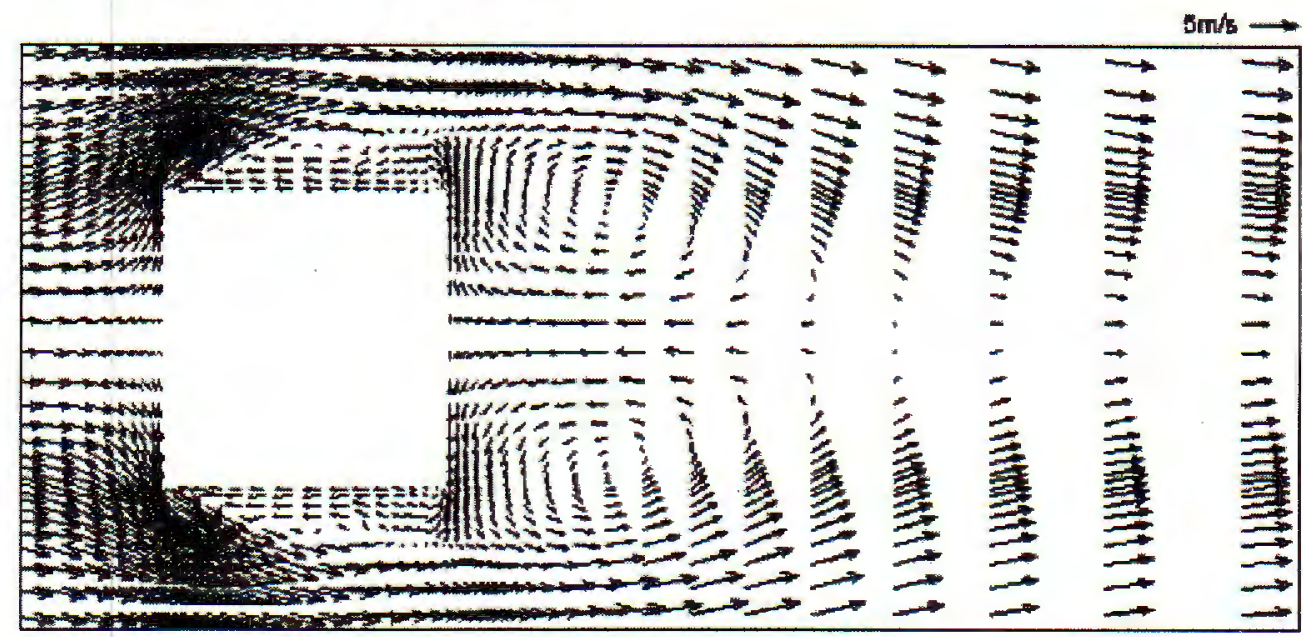

Fig. 3. Velocity vector field in $x-y$ through the center of building for $z_{0}=0.001 \mathrm{~m}$ and $u_{H}=7 \mathrm{~m} / \mathrm{s}$

\subsection{The effect of temperature gradient in stable atmospheric boundary layer}

It is well known that the vertical gradient of potential temperature $\theta$ has very significant effects on the atmospheric flow. The importance of the vertical gradient of $\theta$ in the atmospheric boundary layer lies in the relation with thermal stability criteria. Thefore, investigating the influence of $\frac{\partial \theta}{\partial z}$ on the recirculation zone's length is one of the objectives in this study. Firstly, this investigation is limited in the neutral and stable atmospheric boundary layer, i.e. $\frac{\partial \theta}{\partial z} \geq 0$.

Three sets of numerical simulation using different approach flow were carried out. These three sets of numerical simulation were performed with three different aerodynamic roughness lengths. The surface friction velocity held fixed $(0.15 \mathrm{~m} / \mathrm{s})$. According to Garrat [12], three values of aerodynamic surface roughness are chosen:

1. $z_{0}=0.001 m-$ smooth soil surface.

2. $z_{0}=0.05 m$ - roughness soil surface or thick grass surface.

3. $z_{0}=0.05 m-$ thin grass surface.

In each set of numerical simulation, there are eight numerical simulations using different vertical gradients of the potential temperature, ranging from $\frac{\partial \theta}{\partial z}=0^{\circ} \mathrm{K} / \mathrm{m}$ (neutral) to $\frac{\partial \theta}{\partial z}=0.15^{\circ} \mathrm{K} / \mathrm{m}$ (extremely stable). It is neccesary to note that the vertical gradient of potential temperature is almost always smaller than $15^{\circ} \mathrm{K} / 100 \mathrm{~m}$ 
[12]. The calculated length of the recirculation zone behind the building as a function of $\frac{\partial \theta}{\partial z}$ is plotted in Figure 4 for these three sets of numerical simulation. The calculated results show that the length of the recirculation zone decreases with the increase of $\frac{\partial \theta}{\partial z}$, i.e. the length of recirculation will decrease if the atmospheric stability increases. The atmospheric stability also strongly influences to the structure of the flow in recirculation zone. Under neutral and slightly stable conditions, nearly horizontal flow is observed behind the building, whereas under the strongly stable condition, clear down flow is observed. Extremely strong thermal stability dramatically suppress the recirculation zone behind the building, especially at the distances far from the lee side of the building.

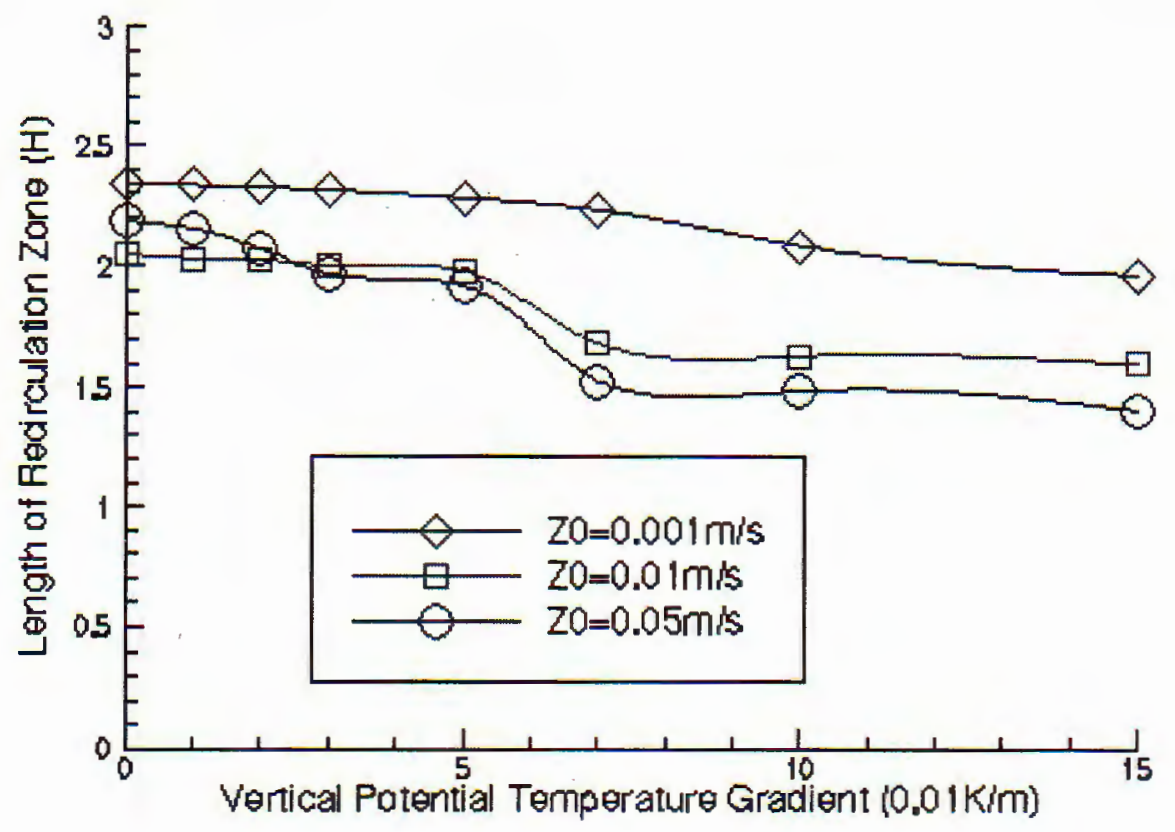

Fig. 4. The length of the recirculation zone as a function of the vertical potential temperature gradient

\subsection{The effect of surface roughness}

The surface roughness is direct cause of the nonuniform vertical structure of wind speed in the atmospheric boundary layer. The logarithmic wind law (2.13) involves the aerodynamic roughness length parameters, which are determined by the physical nature of the ground surface.

The effect of the surface roughness on the length of the recirculation zone can also be seen in Figure 4. In general, the length of the recirculation zone will decrease if the surface roughness increases. However, there are some cases which do not follow this tendency. These occur in three cases of high surface roughness $\left(z_{0}=0.05 \mathrm{~m}\right)$ 
and neutral or slightly stable conditions $\left(\frac{\partial \theta}{\partial z} \leq 0.03^{\circ} \mathrm{K} / \mathrm{m}\right)$. From the observation of the simulated flow fields, it was found that this exception has a concern with the transition of the structure of the recirculation zone behind the building.

The velocity vector fields in the vertical plane through the center of building for $z_{0}=0.001 \mathrm{~m}, 0.01 \mathrm{~m}$ and $0.05 \mathrm{~m}$ in the neutral condition are shown in Figure 5. It is clear that there are some differences in the structure of the recirculation zones among these three simulated results. In the case of $z_{0}=0.001 \mathrm{~m}$, the velocities in the reversed flow region are nearly horizontal, but the reversed velocities are more vertical in the cases of higher surface roughness. In the vertical plane through the center of building, only one vortex can be seen in Figure 5 for $z_{0}=0.001 \mathrm{~m}$ and $z_{0}=0.01 \mathrm{~m}$, whereas two vortices can be seen for $z_{0}=0.05 \mathrm{~m}$. The unique vortex for the cases of $z_{0}=0.001 \mathrm{~m}$ and $z_{0}=0.01 \mathrm{~m}$ is clockwise. For the case of $z_{0}=0.05 \mathrm{~m}$, the small vortex near the top-down edge is clockwise and the larger one is counter-clockwise. A transition between two above structures occurs at a threshold aerodynamic surface roughness between $0.01 \mathrm{~m}$ to $0.05 \mathrm{~m}$.

\subsection{Comparison of the length of recirculation zone for the different roughness surface with the same wind speed at the building height}

Indeed, the surface roughness influences to the wind speed at every height of the atmospheric boundary layer more or less. This influence is formulated in the logarithmic wind law (2.13). According to the numerical simulations described in the Section 3.3, it was concluded that the length of recirculation will decrease if the surface roughness increases. It is easy to understand this behaviour, because in according to this the wind speed at the same height will decrease when the surface roughness increases.

However, in reality, the wind speed is usually known at a fixed height above the ground surface, for example, at $z=10 \mathrm{~m}$. Therefore, it is necessary to know the influence of the surface roughness to the length of the recirculation zone with the same wind speed at a given height. To understand this, three numerical simulations are performed with the same wind speed at the building height $H=60 \mathrm{~m}: u_{H}=$ $7 \mathrm{~m} / \mathrm{s}$ and the aerodynamic surface roughness $z_{0}=0.001 \mathrm{~m} ; 0.01 \mathrm{~m}$ and $0.05 \mathrm{~m}$.

In according to these three calculations, the length of the recirculation zone behind the building equal $1.776 \mathrm{H}, 1.782 \mathrm{H}$ and $2.304 \mathrm{H}$, respectively, i.e. the length of the recirculation zone for the case with smaller aerodynamic surface roughness is shorter. From the numerical results it can be seen also that the influence of $z_{0}$ is not noticeable in the range from $z_{0}=0.001 \mathrm{~m}$ to $z_{0}=0.01 \mathrm{~m}$, but very noticeable in the range from $z_{0}=0.01 \mathrm{~m}$ to $z_{0}=0.05 \mathrm{~m}$.

\subsection{The effect of the variation of the building height}

In the numerical studies, which are described in the previous sections, the cubical building was chosen to investigate the effects of some important factors. However, it is easy to believe that the the recirculation zone behind the building will be change 
(a)

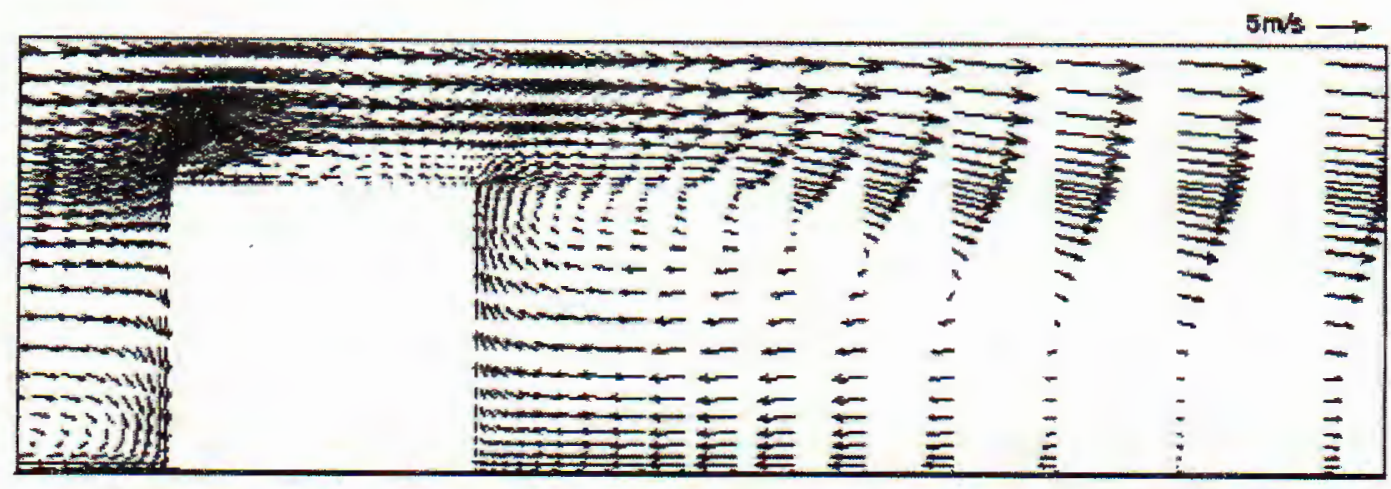

(b)

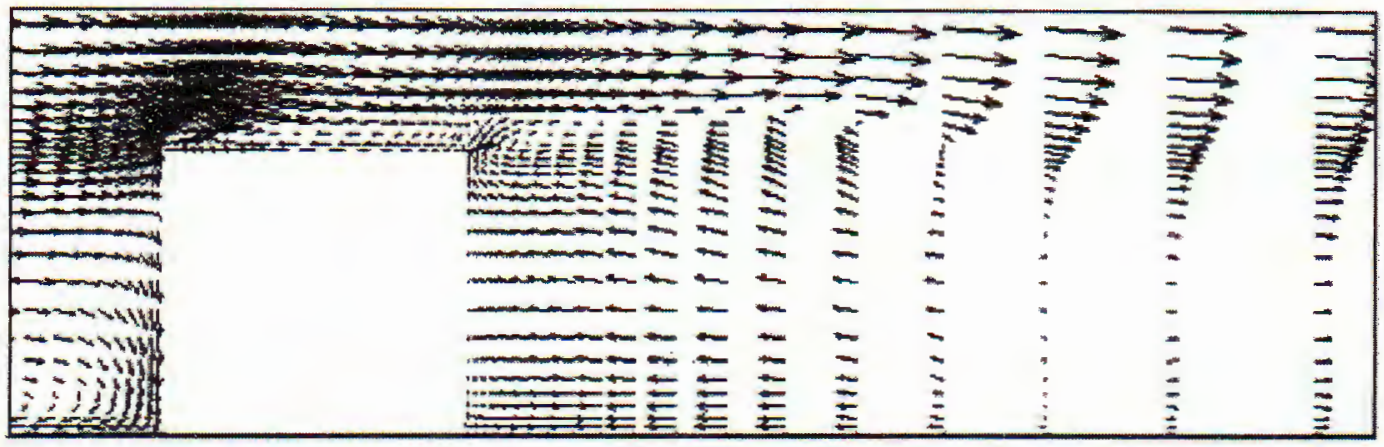

(c)

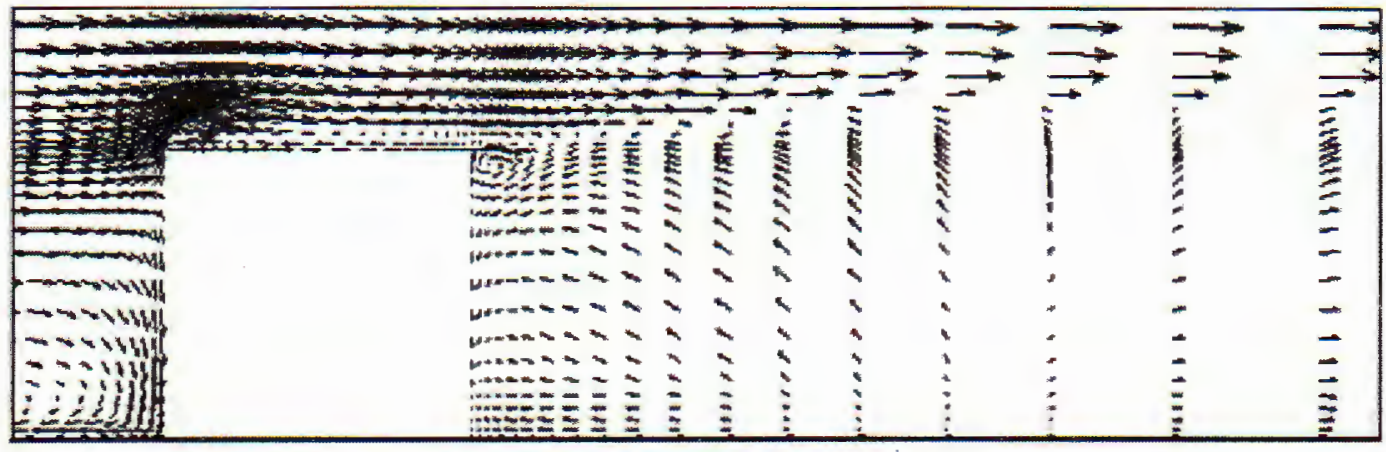

Fig. 5. Velocity vector field in $x-z$ plane through the center of building $u_{* 0}=0.15 \mathrm{m.s}$ :

(a) $z_{0}=0.001 \mathrm{~m}$, (b) $z_{0}=0,01 \mathrm{~m}$, (c) $z_{0}=0.05 \mathrm{~m}$

more or less if the height of building increases or decreases. To investigate this effect, three numerical simulations are carried out for the new heights of the building $H_{B}$, which are chosen to be equal $0.5 \mathrm{H}, 1.5 \mathrm{H}$ and $2 \mathrm{H}$. The approach flows for these numerical simulations are completely equivalent to the approach flow of the first set presented in the Section 3.2. These simulations are carried out for the neutral atmospheric boundary layer.

The velocity vector fields in the vertical plane through the center of building are shown in Figures $6 \mathrm{a}-\mathrm{c}$ for the cases of $H_{B}=0.5 \mathrm{H}, H_{B}=1.5 \mathrm{H}$ and $H_{B}=2 \mathrm{H}$, respectively. For the case of $H_{B}=H$, the velocicy vector field has been plotted in Figure 5a. 
(a)

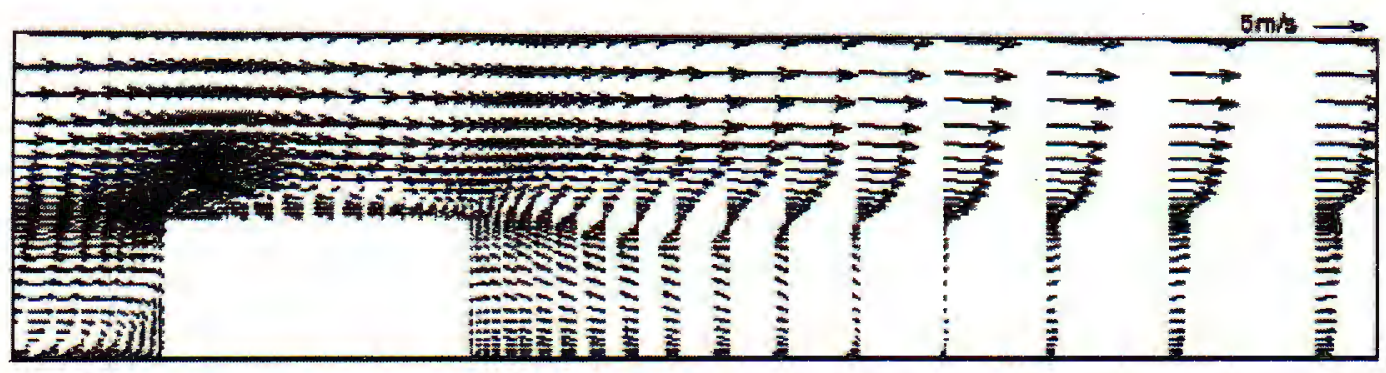

(b)

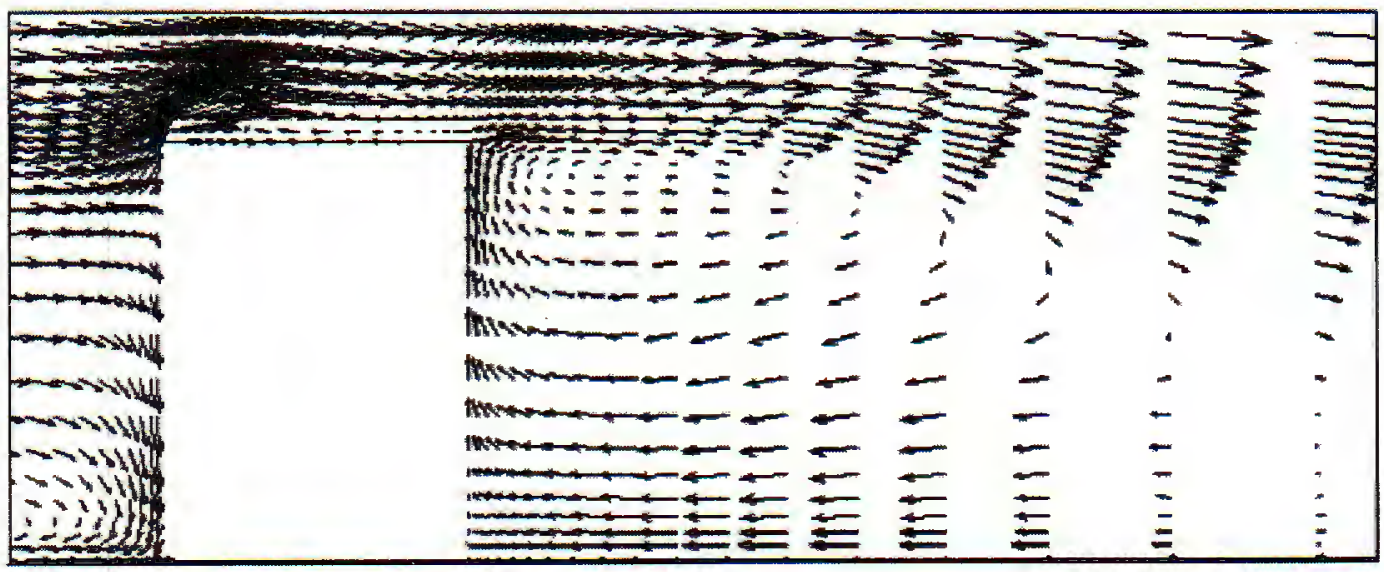

(c)

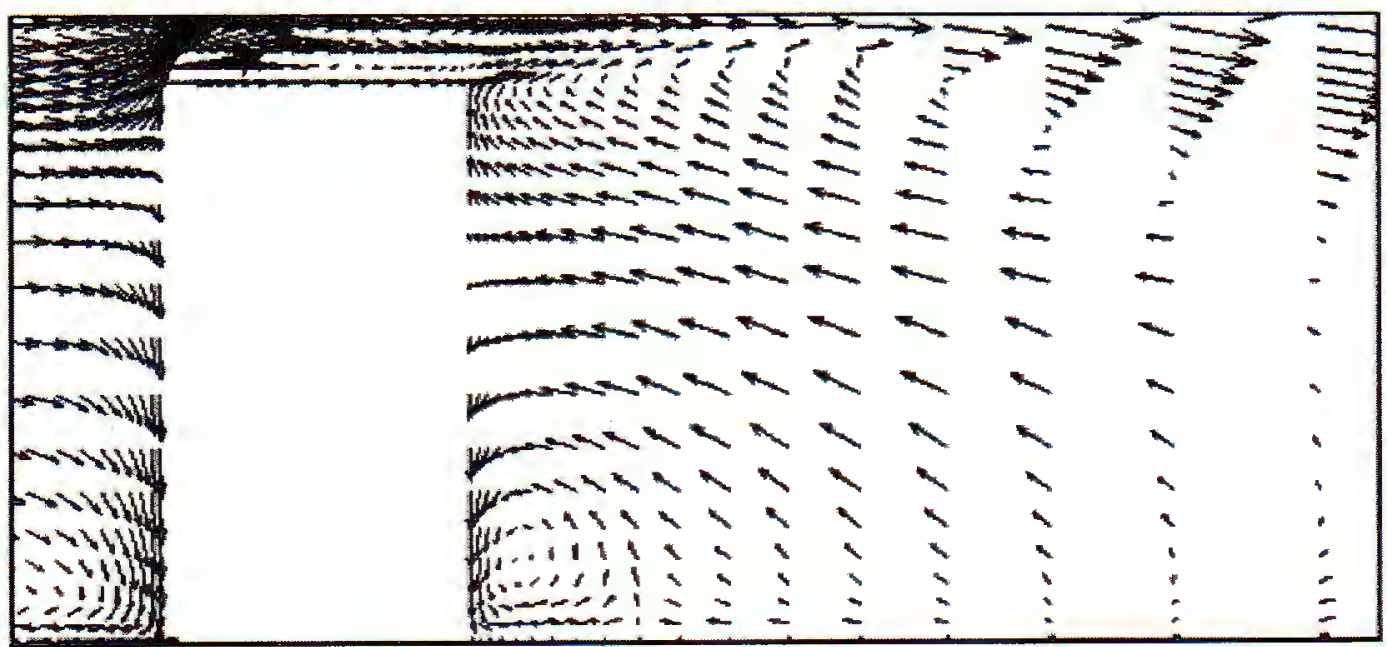

Fig. 6. Velocity vector field in $x-z$ plane through the center of building $u_{H}=7 \mathrm{~m} / \mathrm{s}$ and $z_{0}=0.001 \mathrm{~m}$ : (a) $H_{B}=0.5 \mathrm{H}$, (b) $H_{B}=1.5 \mathrm{H}$, (c) $H_{B}=2.0 \mathrm{H}$

From the calculated results, it can be seen that the lengths of the recirculation zone, which refer to the distance from the lee side of the building to the farthest point having the reversed velocity, for the cases of $H_{B}=0.5 H, H_{B}=H, H_{B}=1.5 H$ and $H_{B}=2 H$ equal $1.907 \mathrm{H}, 2.343 \mathrm{H}, 2.570 \mathrm{H}$ and $2.547 \mathrm{H}$, respectively. To show this effect more clearly, the dependence of the length of the recirculation zone on the height of the building was plotted in Figure 7. It is necesssary to note that, in 
this study, it keeps constant (and equal) for either the width or the length of the building.

Figure 7 showed that the length of the recirculation zone behind the building strongly increases with increasing $H_{B}$ from 0 to $H$, and slowsly increases with increasing $H_{B}$ from $H$ to $1.5 \mathrm{H}$ and, surprisingly, slightly decreases with increasing $H_{B}$ from $1.5 \mathrm{H}$ to $2 \mathrm{H}$.

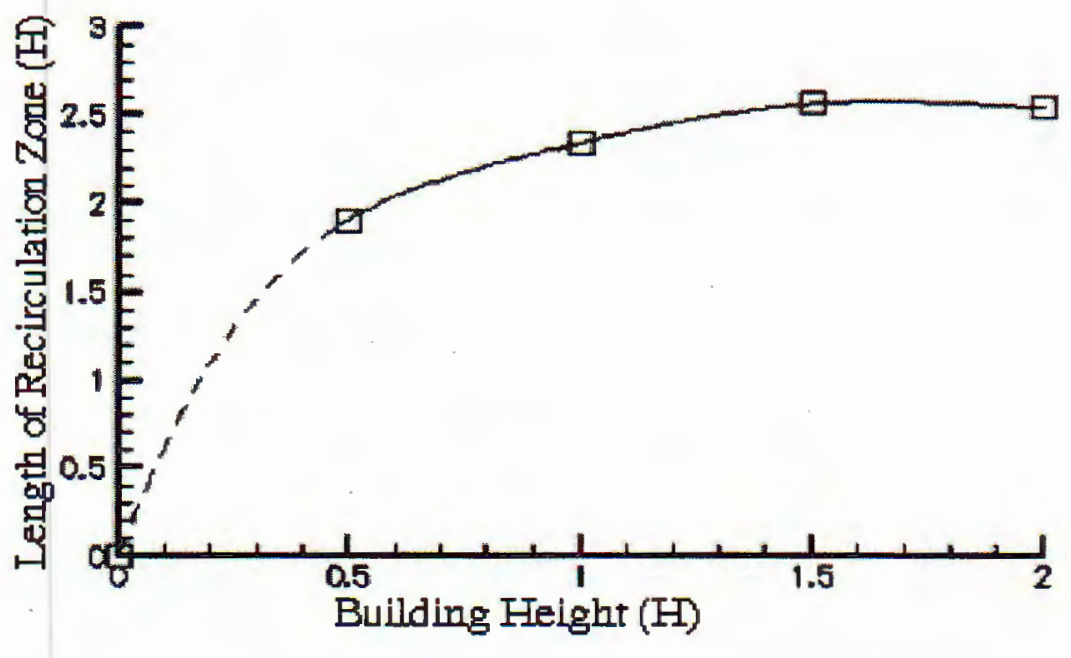

Fig. 7. The length of the recirculation zone as a function of the height of the building, $H$ stand for either the width or the length of the building

The slightly decrease of the length of the recirculation zone as $H_{B}$ increases from $1.5 \mathrm{H}$ to $2 \mathrm{H}$ can be understood from Figures 6 and Figure 5a. The structure of the recirculation zone in the case of $H_{B}=2 H$ is clearly different from the structures of the recirculation zone in the cases of $H_{B}<2 \mathrm{H}$. In the central section through the building center, only one vortex is observed in the cases of $H_{B}=0.5 \mathrm{H}, H_{B}=H$ and $H_{B}=1.5 \mathrm{H}$, whereas two vorties are observed in the case of $H_{B}=2 \mathrm{H}$. A transition from 'one-vortex' flow structure to 'two-vortex' flow structure occurs at a threshold ratio $\left(H_{B} / H\right)$ between 1.5 to 2 . It is neccesary to note that the words 'one-vortex' and 'two-vortex' only refer to the observation in the central vertical plane, because the observed and calculated three-dimensional vortices is usually very complicated. It is clearly that, beside the height, the width of the building also have strong influence on the structure and size of the zone of recirculation flow. In this concern, the thickness of the building may have less important role.

\section{Conclusions}

In this study, the recirculation zone behind the building was investigated using a three-dimentional non-hydrostatic model with the $k-\varepsilon$ turbulent closure scheme. The Duynkerke's modifications of the equations for the atmospheric application 
were used. Several series of numerical simulations have been performed in order to investigate the effect of approach flow velocity, thermal stable degree, surface roughness and height of building.

The results of numerical simulations show that with keeping the same the other parameters the length of the recirculation zone behind the building will increase as the wind speed inreases, and, in the presented in the paper example, will approach to an asymptotic value $\sim 2.5$ times of the height of cubical building.

The study also indicated that the length of the recirculation zone will decrease as the vertical gradient of the temperature increases. The strong thermal stability will suppress not only the length but also the height of the recirculation zone behind the building (i.e. it change the wake zone configuration). The recirculation zone's length and associated parameters become weakly dependent on $\frac{\partial \theta}{\partial z}$ when this value is greater than $10^{\circ} \mathrm{K} / 100 \mathrm{~m}$.

The effects of the surface roughness on the flow behavior behind a building are more complex than the effects of the wind speed and the vertical gradient of the temperature. In general, the length of the recirculation zone will decrease as the surface roughness increases. However, in some cases, this length will increase as the the surface roughness increases. This exception from the general tendency concerns with a transition (in the central vertical plane through the building center) from the simple 'one-vortex' structure to the complex 'two-vortex' structure of the flow field in the recirculation zone. The complex 'two-vortex' structure may occurs in the case with a high value of the aerodynamic surface roughness in the neutral or slightly stable atmospheric boundary layer.

Indeed, the wind speed at reference height will decrease as the surface roughness increases. Therefore the effects of the surface roughness will include the effects the wind speed more or less. From the results of the numerical simulation, this study also noted that for the approach flows, which have the same wind speed at a fixed height, the longer length of the recirculation zone correspond to the higher value of the surface roughness.

In addition to the numerical simulations for the building of cubical shape, the height of the initial building also is changed in some simulations (at the same time its width and thickness are kept constant) to investigate the effects of the variation of the building height. The results of the numerical simulations show that the length of recirculation zone will strongly decrease as the height of the initial cubical building decreases. Clearly, there is not the recirculation zone $\left(L_{r}=0\right)$ when $H_{B}=0$. At the same time, as the height of the initial building increases (and the width and thickness are constant), the length of the recirculation zone will only slowly increase to a maximum value $\sim 2.5$ times of the heigh of the initial cubic. A transition from simple 'one-vortex' structure to complex 'two-votex' structure occurs at a threshold value of the building ratio (height/width) between 1.5 to 2 . After this transition, the length of the recirculation zone slightly decreases. 
The study is implemented with the partly financial support from the Vietnam National Council of Natural Sciences.

\section{REFERENCES}

1. Costa M. J., Riethmuller M. L. and Borrego C. Wind-tunel simulation of gas dispersion over complex terrain: Comparison of two length-scale studies. Atmos. Environ., Vol. 28, No. 11, pp. 1933-1938, 1994.

2. Winson D. J. and Chui E. H. Influence of Building Size on rooftop dispersion of exhaust gas. Atmos. Environ., Vol. 28, No. 14, pp. 2325-2334, 1994.

3. Mirzai M. H., Harvey J. K. and Jones C. D. Wind tunel investigation of dispersiopn of pollutants due wind flow around a small building. Atmos. Environ., Vol. 28, No. 11, pp. 1819-1826, 1994.

4. Duong Ngoc Hai, Nguyen The Duc, Le Trinh. Wind Field over Complex Terrain and Air Quality Modeling. J. Mech., Vol.XIX, No.4,pp. 29-38, 1997.

5. Physick W. L. Review: Mesoscale Modelling in Complex Terrain, Earth-Science Reviews, pp. 199-235; 1995.

6. Leone J. M. and Robert L. Lee. Numerical Simulation of Drainage Flow Brush Creek, Colorado, J. App. Meteor., 28, pp. 530-542, 1989.

7. Abbs D. J. and Physick W. L. See-breeze observations and modelling-areview, Aust. Met. Mag. 41, pp. 7-19, 1992.

8. Physick W. L. et al. LADM: A Lagrangian Atmospheric Dispersion Model. CSIRO Division of Atmospheric Research Technical Paper No.24, CSIRO Australia, 1994.

9. Clack T. L. A Small-scale Dynamic Model Using a Terrain-Following Coordinate Transformation. J. Comp. Phys., Vol. 24, pp. 186-215, 1977.

10. Mellor G. L. and Herring H. J. A Survey of the Mean Turbulent Field Closure Models. AIAA Journal, Vol. 11, No. 5, pp. 591-599, 1973.

11. Rodi W. Turbulence Models for Environental Problems. In Prediction Methods for Turbulent Flows, Ed. by Kollmann W., Hemisphere Publishing Corporation, Washington, 1980.

12. Garrat J. R. The atmospheric boundary layer. Cambridge University Press, New York, 1992.

13. Detering, H. W., and D. Etling. Application of the turbulence model to the atmospheric boundary layer. Bound. Layer Meteor., Vol. 33, pp. 113-133, 1985.

14. Duynkerke P. G. Application of the Turbulence Closure Model to the Neutral and Stable Atmospheric Boundary Layer. J. Atmos. Sci., Vol. 45, pp. 865-880, 1988.

15. Patankar S. V. Numerical Heat Transfer and Fluid Flow. McGraw-Hill, New York, 1980. 
16. Ferziger J. H. and M. PeriD. Computational Methods for Fluid Dynamics. Springer - Verlag, Berlin Heidelberg, 1996.

17. Duong Ngoc Hai, Nguyen The Duc. A Three Dimensional Non-Hydrostatic Model for Turbulent Air Flow. J. Mechanics, Vol. 22, No.3, 2000.

18. Duong Ngoc Hai and Nguyen The Duc. An Evaluation About Two Modifications of the Standard Model for Numerical Simulation of Turbulent Air Flow. Proc. of 2nd International Symposium on Modeling Simulation. Hanoi, Dec., 2000.

19. Duong Ngoc Hai, Nguyen The Duc. Three Dimensional Non-Hydrostatic Model of Turbulent Atmospheric Boundary Layer. In: Proc. of the 8-th Intern. Symposium on Flow Modelling and Turbulent Measurement, Tokyo - FMTM 2001, Springer Verlag, Berlin - Heidelberg, 2002.

20. Tennekes H. The Logarithmic Wind Profile. J. Atmos. Sci., Vol. 30: 234-238, 1973.

21. Baik J. J. and Kim J. J. A Numerical Study of Flow and Pollutant Dispersion Characteristics in Urban Street Canyons, J. Appl. Meteo., 38(11), pp. 1576-1589, 1999.

22. Sini J. F. et al. Pollutant dispersion and thermal effects in urban street canyons. Atmos. Environ. Vol. 30, No. 15, pp. 2659-2677, 1996.

Received May 8, 2002

\section{NGHIÊN CÚU SỐ VÙNG QUẢN GIÓ SAU MỘT TÒA NHÀ TRONG CÁC ĐIỀU KIỆN KHÍ QUYE̊̉N TRUNG TÍNH VÀ ỔN ĐỊNH}

Bài báo trình bày các nghiên cứu số sử dụng mô hình $k-\varepsilon$ vùng quẩn gió sau vật cản hình hộp trong điều kiện khí quyển trung tính và ổn định. Những ảnh hưởng của vận tốc gió, gradient nhiệt độ theo chiều đứng, độ ráp bề mặt và chiều cao của tòa nhà hình hộp được nghiên cứu. Kết quả nghiên cứu cho thấy rằng đối với vật cản dạng hình hộp vuông, vùng quẩn gió trải rộng từ ngay sau vật cán tới một vị trí cách vật cản tối đa khoảng 2.5 lần kích thước vật cản. Độ dài vùng quẩn gió tăng lên khi vận tốc gió tăng lên, giảm đi khi gradient nhiệt độ theo chiều đứng tăng lên, giảm đi khi bề mặt ráp hơn và tăng lên khi chiều cao của tòa nhà hình hộp tăng lên. Hai khuynh hướng chung cuối nói trên đôi khi không còn hoàn toàn đúng cho những trường hợp bề mặt có độ ráp cao hoặc chiều cao của tòa nhà lớn. Trong những trường hộp đó, dòng chuyển từ cấu trúc 'một xoáy' đơn giản sang cấu trúc 'nhiều xoáy' phức tạp.

Institute of Mechanics, NCNST

264, Doican Str., Hanoi, Vietnam

Email: dnhai@im01.ac.vn 